\title{
INSTRUCTIONS FOR CONTRIBUTORS
}

AIMS AND SCOPE

Organised Sound is a fully peer-reviewed scholarly journal focusing on the rapidly developing methods and issues arising from the use of contemporary technology in fields such as multimedia, performance art, sound sculpture and electroacoustic composition. It is a forum for music scholars, composers, performers, computer specialists, mathematicians and engineers to share the results of their research as they affect musical issues. Young researchers will be particularly encouraged. Contributors are encouraged to submit sound examples and multimedia material for the online version of the journal.

\section{SUBMISSION}

Submission of a paper to Organised Sound is held to imply that it represents an original contribution not previously published and that it is not being considered elsewhere. Papers are reviewed by at least two referees.

Papers should be submitted by email to os@dmu.ac.uk.

\section{Leigh Landy}

Organised Sound

De Montfort University, Clephan Building, Leicester LE1 9BH, UK.

$$
\text { email: os@dmu.ac.uk }
$$

Papers should not normally exceed 7000 words and should be preceded by an abstract of approximately 200 words.

Please contact the editor if you have sound or movie examples. See further information concerning sound and movie examples below.

\section{MANUSCRIPT REQUIREMENTS}

Manuscripts should be submitted electronically to the editors as Word files. The journal initials OS and 6 characters of the author surname should be used as the file name, plus .doc, e.g OSjones.doc would be a typical file name.

Where Mac files are submitted these should be .rtf files and similarly OSjones.rtf should be the file name.

Only final material should be submitted; no draft material is accepted. The author affiliation, full postal address and email address to which proofs should be sent should start the file. The contributor should keep a back-up file.

Illustrations should be submitted as individual eps or tif files in separate files from the text and labelled similarly JonesF3.eps, etc. No author graphics programs can be handled. Colour files should not be submitted; the journal uses only black and white reproductions and all colour images should be converted to black and white before submission to check that all features are present when colour is not used. Very large files can be zipped. The normal reproduction of halftones for printing is at 300dpi and line artwork at $1200 \mathrm{dpi}$. Low resolution illustrations may be rejected by the editor.

Please note that it is each author's sole responsibility to gain copyright permission for images, sound and movie examples.

Sound and Movie Examples should be submitted digitally in MP4 and M4V formats respectively. The total duration for a given submission should normally not exceed 15 minutes (sound examples) or 8 minutes (movie examples). All media examples should also be made available online for peer review.

Footnotes should be kept to a minimum. Note indicators in the text should follow punctuation. Any acknowledgements should appear at the end of the article.

Bibliographical references should be given in parentheses in standard author-date form in the body of the text: (Lee and Devore 1968: 236). When a work is written by three or more authors, all names should be given in the first citation: (Fraser, Brown and Smith 1989). In subsequent citations, the first name only should be given with et al. added. A group of references within the text should be date ordered, the earliest first.

A complete list of references cited, arranged alphabetically by author's surname, should be typed double-spaced at the end of the article. This list must contain all the works cited in the text, and only those works. Contributors are asked to standardise on basic conventions:

- make all journal numbers arabic

- do not use pp. before page numbers if the volume number is also given - make the titles of published works italic (not bold) by underlining or using an appropriate word processor font

- do not use inverted commas around chapter titles in edited books, journal articles, and the titles of unpublished dissertations
- elide page numbers to the shortest pronounceable form: 56-7, 281-3, but 215-16

- include an 'accessed on' date when a specific article has been cited, but not for general websites (e.g. www.cambridge.org).

Examples of references:

Book, article, article in edited book, unattributed website, attributed website, proceedings article, email, letter, hypermedia document, score. Weidenaar, R. H. 1995. Magic Music from the Telharmonium. Metuchen, NJ: The Scarecrow Press.

Davies, H. 1996. A History of Sampling. Organised Sound 1(1): 3-11. Varèse, E. 1936. New Instruments and New Music. In E. Schwartz and B. Childs (eds.) Contemporary Composers on Contemporary Music. New York: Norton, 1967.

ElectroAcoustic Resource Site (EARS). 2002. http://www.ears.dmu. ac.uk (accessed 5 August 2009).

Kunst, J. 1986. Social Cognitions and Musical Emotions. http://www. joskunst.net/social_cognitions.html (accessed on 5 August 2009). Young, J. 2002. The Interaction of Sound Identities in Electroacoustic Music. Proceedings of the 2002 International Computer Music Conference. Göteborg/San Francisco: ICMA, 342-8.

Budney, G. 2015. Interview by the author(s), Cornell Lab of Ornithology, 5 October.

Falls, J. B. 2016. Email correspondence with author(s), 26 July. Bossis, B. 2000. Analyse de Mortuos Plango, Vivos Voco de Jonathan Harvey. Hypermedia document. Paris: Médiathèque de l'IRCAM. Sciarrino. S. 1992. Perseo e Andromeda. Milan: Ricordi, score 135358.

Example of a discography entry:

Smalley, D. 1992. Wind Chimes (1987). On Impacts intérieurs. Montreal: Empreintes Digitales, IMED-9209-CD.

Punctuation should follow standard British practice. Single quotation marks should be used with double reserved for quotations within quotations. Punctuation that is not part of the quoted material should be outside closing quotation marks, as should footnote indicators. Longer quotation should be indented left without quotation marks and double spaced. Prose citations should be in English unless the original is of particular importance, unpublished or inaccessible, in which case the original should be follow by a translation in square brackets.

Contractions and acronyms should have no full points (Dr, DAT), but abbreviations and their plurals should retain them (vol., vols., ed., eds.).

Tables should be clearly laid out on separate pages, numbered consecutively, and designed to fit the printed page. Vertical lines should not be used and horizontal lines should be used only at the top and bottom of the table and below column headings.

Captions should be on a separate page, double spaced. Indicate in square brackets in the typescript, or in the margin, approximately where in the text tables and illustrations should fall.

Subheadings should be typed with prefatory numbers indicating the level of importance, $1,1.1,1.1 .1$. No more than three levels of subheading should normally be used.

Quotations. Single inverted commas should be used except for quotations within quotations, which should have double inverted commas. Longer quotations of more than 60 words, or quotations which are of particular importance should be set off from the text with an extra line of space above and below, and typed without inverted commas.

Spelling. The journal employs British English spelling conventions.

Idiomatic English. We welcome and encourage submissions from non-native speakers of English. However, every effort should be made by non-native speakers of English to have their final draft checked by a colleague who is a native speaker of English. Manuscripts may be sent back to the author(s) if serious language deficiencies remain in the text.

PROOFREADING

First proofs may be read and corrected by contributors provided that they can guarantee to return the corrected proofs, by airmail when appropriate, within four days of receipt. Contributors should correct printers' errors but not introduce new or different material at this stage.

OFFPRINTS

Contributors will receive a PDF offprint of their article when it is published. 


\section{CONTENTS}

Editorial

Failed Histories of Electronic Music

Daniel R. Wilson

Inaudible Visitors: Theories of sound reproduction

in the studio practice of Pierre Schaeffer

Reuben de Lautour

'There Must Be a Poetry of Sound That None of Us

Knows...': Early British documentary film and the

prefiguring of musique concrète

Geoffrey Cox

The Forgotten History of Repetitive Audio Technologies

Christophe Levaux

Loudspeakers Optional: A history of

non-loudspeaker-based electroacoustic music

Jason Long, Jim Murphy, Dale Carnegie and Ajay Kapur

A Day in Algonquin Park: William W. H. Gunn and

the circadian audio portrait

Laura Cameron and Matt Rogalsky

The Don Banks Music Box to The Putney:

The genesis and development of the VCS3 synthesiser

James Gardner

Canonisation and Documentation of Interdisciplinary

Electroacoustic Music, Exemplified by Three Cases

from the Netherlands: Dick Raaijmakers,

Michel Waisvisz and Huba de Graaff

Hannah Bosma

Pioneer Spirits: New media representations of

women in electronic music history

Frances Morgan

'Nimble Fingers' in Electronic Music: Rethinking

sound through neo-colonial labour

Lucie Vágnerová

A History of Electronic Music at the University of lowa

Paul Duffy

Electroacoustic Feedback and the Emergence of

Sound Installation: Remarks on a line of flight in the

live electronic music by Alvin Lucier and Max Neuhaus Matthieu Saladin

Across Fields: Sound, art and technology from an

electromechanical perspective

Jon Pigott

Music without Musicians ... but with Scientists,

Technicians and Computer Companies

Giuditta Parolini

Early Computer Music Experiments in Australia

and England

Paul Doornbusch

Book review 